$\xi=-1$

\title{
Radon Gas Adsorption Properties of Non-Cement Matrix Using Anthracite
}

\author{
Hyun-Ung Lim', Su-Jeong Pyeon ${ }^{2}$, Sang-Soo Lee ${ }^{3 *}$ \\ ${ }^{1,2,3}$ Department of architectural engineering, Hanbat national univ., S.Korea \\ *Corresponding author E-mail: sslee111@hanbat.ac.kr
}

\begin{abstract}
Background/Objectives: Recently, research on minimizing the exposure of radon in human environment is under way due to the threat of exposure to radiation, which is a problem in the world.

Methods/Statistical analysis: This study is about the production of Radon Radiation Absorbing Hardeners for radon - emitting materials in indoor environment of human body. The anthracite used as a conventional filter medium was used as a radon adsorbent and the characteristics of an adsorbed cured body for the replacement ratio of anthracite were analyzed.

Findings: As a result of the analysis of the experimental results, the results of the measurement of the radon gas concentration are as follows. And the adsorption effect on the half - life period of 3.8 days of radon gas was investigated. The adsorption properties of radon gas showed similar tendency irrespective of the measurement period. The longer the period, the more the concentration of radon gas was constant.

Improvements/Applications: As a result of this study, the concentration of radon gas tended to decrease as the anthracite replacement ratio increased, which was not related to the duration of the measurement period of 3 days and 7 days. It is considered that the average data analysis is needed through long-term measurement of radon gas, and additional experiments are required considering the space and spatial characteristics. In addition, performance evaluation of other adsorbents is also considered necessary.
\end{abstract}

Keywords: Indoor air quality, Radon gas, Absorption, Non-cement matrix, Anthracite

\section{Introduction}

Recently, the risk of radioactive materials has become a hot topic. Starting with the Chernobyl nuclear accident in 1996, it suffered major damage in 2011, such as the accident at the Fukushima nuclear power plant in Japan, and the selection of a dangerous area to control access for several decades. In Korea, concern about the release of radioactive materials due to recent earthquakes has been deepening in the Wolsong nuclear power plant in Gyeongju, and the public is increasingly interested in the safety of radioactive materials through media and media. However, the route to exposure to radioactive materials is not limited to these large-scale nuclear accidents. Typical examples of this are radioactive substances exposed in daily life.[1] Radon, one of the natural radionuclides on the earth, is a lung cancer causing gas, which is a colorless, tasteless, odorless. Naturally occurring radioactive gas and is produced by the decay of radionuclides of uranium in the crust and soil. It has been scientifically proven that radon gas and its decaying short-half-life radionuclides are at risk for lung cancer if they are long-term accumulated in the body through respiration. When the human bodybreathe, radon and radionuclides enter the respiratory tract by inhalation and adsorb to lung tissue. In addition, fine dust such as aerosol introduced at this time also helps to adsorb radon gas and sticks to the lung tissue. Normal dirt or particles are excreted again by exhalation, but in the case of radon, it attaches to the bronchi and lungs and then collapses. In the process, it releases radiation called alpha rays, which directly impairs lung tissue. These natural radionuclides are a part of the living environment of human beings (about 55\% of the dose of natural radionuclide radiation, which acts as part of human life environment).It was found that human beings were $10 \sim 100$ times higher than the average radiation dose due to artificial radiation sources exposed to nuclear industry activities.[2]The purpose of this study is to investigate the properties of non-cement matrix with anthracite with radon gas adsorption to reduce indoor air pollutions generated by radon gas which is the group 1 carcinogen. The adsorption performance of the adsorbent was evaluated by using anthracite which is a kind of conventional filter media.[Figure 1] shows the range of radon gas concentration and action levels.

\section{Experimental Synopsis}

As shown in [Figure 2], radon gas has an inflow form through convective movement due to temperature or pressure difference in gas form. The pressure difference between the building and the surrounding soil, the groundwater use, the room is moved to the room by the various facilities in the building, radium is also included in the building materials and household goods.[3] Gaseous behavior for radon gas inflow continues to be maintained in the indoor space and enters the human body through respiration and contact with the human body. Generally, in the adsorption process, the solid is called adsorbate, and the gas or vapor is called adsorbate. The general phenomenon that a solid in the role of adsorbent receives gas is called 'sorption'. The adsorption of adsorbates on adsorbates is related to van der Waals' law and is known as physical adsorption.[4]The physical adsorption is caused 
by mutual attraction between molecules, and the radon gas is adsorbed by attraction force and binding force. In the case of the radon atom, the adsorbed material drifts in the indoor space due to the pressure change and convection movement, and moves to the adsorption surface. $\mathrm{A}$ is the adsorption process due to the impact caused by the inertia force, $\mathrm{B}$ is the trapping phenomenon due to gravity, and $\mathrm{C}$ is the adsorption process based on the blocking phenomenon through the convection movement of the adsorbate.[5]

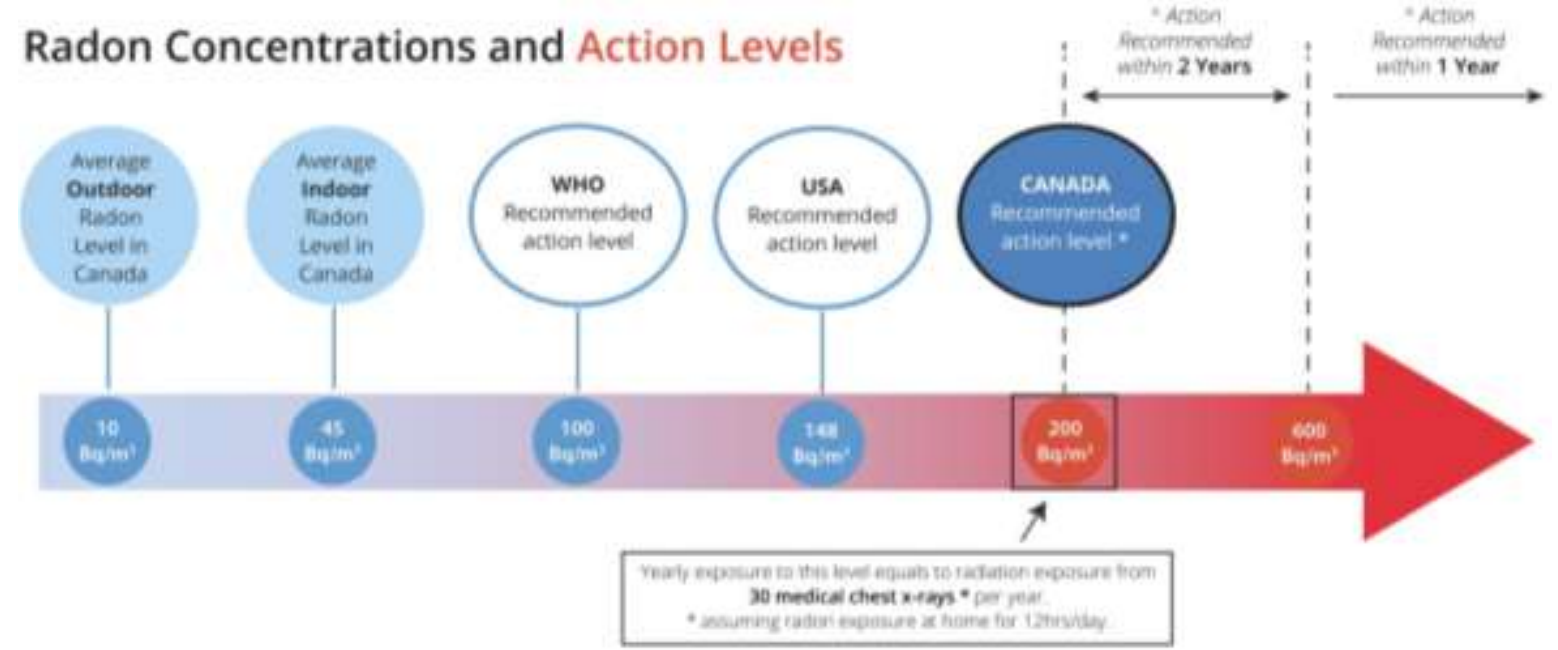

Figure 1: Radon concentrations and action levels by Radontech Solution Inc. (https://radontech.ca/radon-testing-edmonton/)

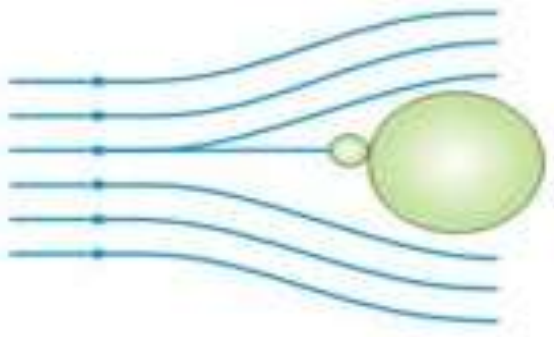

A) Inertial collision

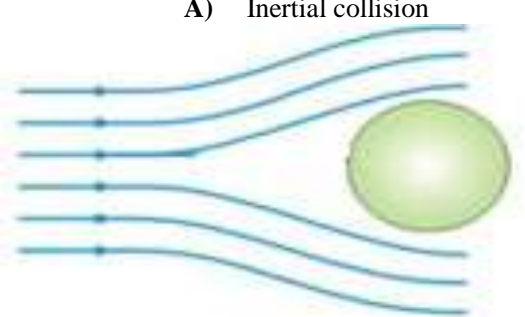

B) Gravity capture

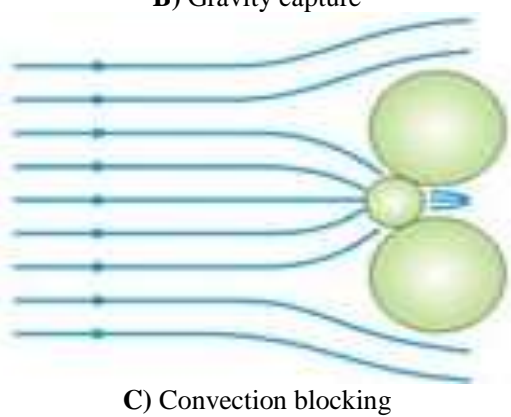

C) Convection blocking

Figure 2: Adsorption mechanism and physical adsorption type (http://webcache.googleusercontent.com/search?q=cache:HVUTYa4xT10J :tex.chonbuk.ac.kr/board/include/download.php\%3Fno\%3D62\%26db\%3D board06\%26fileno $\% 3 \mathrm{D} 1+\& \mathrm{~cd}=14 \& \mathrm{hl}=\mathrm{ko} \& \mathrm{ct}=\mathrm{clnk} \& \mathrm{gl}=\mathrm{kr}$ )

\subsection{Experimental Plan}

The factors and levels of this experiment are shown in [Table 1] The replacement ratio of anthracite to the entire weight was 0,10 , $20,30,40,50(\%)$. Blast furnace slag and $\mathrm{NaOH}$ were used as a binder and alkali stimulant, respectively. The anthracite was replaced on the basis of $100 \mathrm{~g}$ blast furnace slag. Assessment item was radon gas concentration.
Table 1: Experimental Factors and Levels

\begin{tabular}{|c|c|c|}
\hline Experimental factor & Experimental level & \\
\hline Binder & $\begin{array}{l}\text { Blast furnace slag, } \\
\text { Anthracite }\end{array}$ & 2 \\
\hline $\mathrm{W} / \mathrm{B}$ & 32 (wt.\%) & 1 \\
\hline $\begin{array}{l}\text { Alkali activator(NaOH) } \\
\text { addition ratio }\end{array}$ & $12(\%)$ & 1 \\
\hline $\begin{array}{l}\text { Replacement ratio of } \\
\text { anthracite }\end{array}$ & $0,10,20,30,40,50$ (wt.\%) & 6 \\
\hline Curing condition & $\begin{array}{l}\text { Constant } \\
\text { temperature }\left(20 \pm 2^{\circ} \mathrm{C}\right) \text { and } \\
\text { humidity }(80 \pm 5 \%) \text { curing }\end{array}$ & 1 \\
\hline Assessment items & $\begin{array}{ll}\text { Radon } & \text { gas } \\
\text { concentration(3days, } & \\
\text { 7days) } & \\
\end{array}$ & 1 \\
\hline
\end{tabular}

\subsection{Experimental Materials}

\subsubsection{Blast Furnace Slag}

Alkali-activated alumina silicate-based inorganic binders are those in which a material having a composition of alumina silicate exhibits a hydroponic condition in an alkaline environment. In the periodic table, the generation of compounds of Group 3, 4, 5 and 6 elements and hydraulic compounds can produce Group 2 alkaline compounds and other alkaline compounds and hydraulic compounds. That is, it has been confirmed that a hydraulic cured product can be obtained even without using the existing Portland cement. These products have higher strength and durability than concrete using conventional Portland cement.[6] As the alkali activation proceeds, the $\mathrm{pH}$ of the mixture usually remains above 13.5 because the blast furnace slag undergoes the potential hydroprocessing of high concentrations of $\mathrm{OH}-$ in the mixture. In this process, the concentration of $\mathrm{OH}$ - is very high and the film of the blast furnace slag is destroyed and the silicate and the aluminate salt are dissolved in the solution by hydration complex. In this process, condensation of silicate and aluminate anions occurs. The decomposition mechanism of the blast furnace slag depends on the type of $\mathrm{O}$ ions in the blast furnace slag. This is because, depending on the type of bonding, there are occasions between the silicate and the metal ion. [Table 2] shows the chemical and physical composition of the blast furnace slag. [7] 
Table 2: Chemical and physical properties of blast furnace slag

\begin{tabular}{|l|l|l|l|l|l|l|l|l|}
\hline Chemical composition(\%) & \multicolumn{4}{|l|}{$\begin{array}{l}\mathrm{Fens}_{2} \mathrm{O}_{3} \\
\left(\mathrm{~g} / \mathrm{cm}^{3}\right)\end{array}$} & $\mathrm{SO}_{3}$ \\
\hline Used materials & $\mathrm{SiO}_{2}$ & $\mathrm{Al}_{2} \mathrm{O}_{3}$ & $\mathrm{MgO}$ & $\mathrm{CaO}$ & 41.71 & 0.61 & 2.36 \\
\hline Blast furnace slag & 35.08 & 13.87 & 3.60 & 2.91 & \\
\hline
\end{tabular}

\subsubsection{Anthracite}

Anthracite was developed at the University of Pennsylvania State University in the 1930s. It is a kind of filter material manufactured by crushing anthracite with granular or powder. It is used in place of filter paper in large-scale rapid or multi-layer filtration processes of water and sewerage with particulate or powdery filter media. The filtration speed and the throughput can be increased more than two times without deteriorating the water quality because the specific surface area and the porosity are larger than those of the filter paper.
The main component of anthracite is carbon, which is a high carbonaceous coal with high fixed carbon content, which is more resistant to water and chemicals than other materials. As a result, anthracite is not dissolved in alkaline or acidic water, and has a high amount of carbon components and has high corrosion resistance and abrasion resistance. In addition, while the specific gravity of anthracite is much lighter, it has excellent adsorption and deodorization performance and capture ability because it has a large effective diameter and porosity. [Table 3] shows the chemical and physical components of anthracite.[8]

Table 3: Chemical and physical properties of anthracite

\begin{tabular}{|c|c|c|c|c|c|c|c|}
\hline \multicolumn{7}{|c|}{ Chemical composition(\%) } & \multicolumn{1}{c|}{ Density } \\
\hline Used materials & $\mathrm{SiO}_{2}$ & $\mathrm{Al}_{2} \mathrm{O}_{3}$ & $\mathrm{MgO}$ & $\mathrm{CaO}$ & $\mathrm{Fe}_{2} \mathrm{O}_{3}$ & $\mathrm{SO}_{3}$ & $\left(\mathrm{~g} / \mathrm{cm}^{3}\right)$ \\
\hline Blast furnace slag & 22.90 & 7.40 & 1.09 & 10.30 & 24.50 & 0.25 & 0.73 \\
\hline
\end{tabular}

\subsection{Experimental Method}

The following is a schematic diagram of the method for measuring the concentration of radon gas. Since no definite radon gas measurement method has been prescribed at home and abroad, continuous monitoring was conducted using the indoor radon concentration measurement method proposed by Hanbat National University, Korea shown as [Figure 3]. Inside the sealed $500 * 500 * 500(\mathrm{~mm})$ size chamber, measure the radon emission source, the adsorbent, the fan for the convection phenomenon, and the radon gas concentration meter after about 3days( 72 hours) stabilization period. The radon gas, which continues to migrate to the adsorbent surface, will continue its adsorption and reduction processes thereafter.[9]Continuous measurement method was used for measuring the concentration of radon gas and short - term measurement was selected for measurement period. Short - term measurements are possible up to 90 days, and in this study, they are classified into 3 days and 7 days measurements.[10]

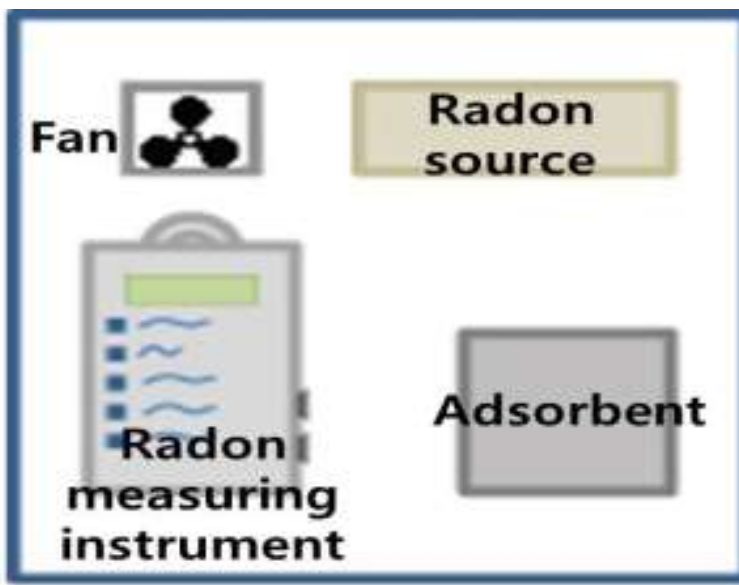

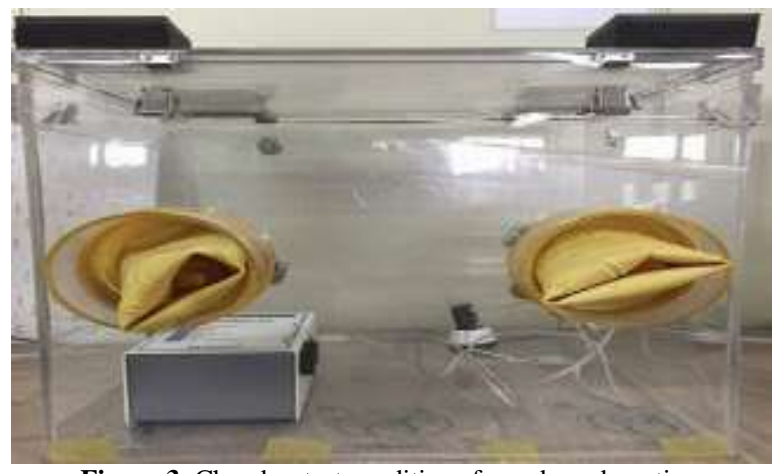

Figure 3: Chamber test conditions for radon adsorption

\section{Experimental Results and Analysis}

\subsection{Radon Gas Concentration}

\subsubsection{Radon Gas Concentration to 3days (72hours)}

It is a result of measured radon gas concentration by putting the radon gas source in the chamber for 3 days and then fixing each matrix in the chamber for 72 hours. The mean value of radon gas concentration of plain matrix was measured as about $54.6 \mathrm{~Bq} / \mathrm{m}^{3}$ at 72 hours. The average value of the anthracite replacement ratio $10 \%$ was measured to be about $324 \mathrm{~Bq} / \mathrm{m}^{3}$ at

72 hours, and the reduction of the lardon concentration was about $154 \mathrm{~Bq} / \mathrm{m}^{3}$ as compared with the plain matrix. The average value of the anthracite replacement ratio $50 \%$ matrix was measured to be about $28 \mathrm{~Bq} / \mathrm{m}^{3}$. The measurement value of the radon gas concentration shows that the concentration of the radon gas decreases as the replacement ratio of the anthracite, which is the adsorbent, increases with the concentration of the radon gas in the air in the chamber where the radon gas particles adhere to the surface of each of the matrix.The following [Table4] is showing the average value of the concentration of radon gas in the chamber per hour, and [Figure 4] graph is a graph showing the trend of the table.

Table 4: The average value of the radon gas concentration in the chamber per hours (3days)

\begin{tabular}{|c|c|c|c|c|c|c|c|}
\hline Level Time & Radon source & Plain & ATC 10 & ATC 20 & ATC 30 & ATC 40 & ATC 50 \\
\hline 3 & 50 & 48 & 26 & 21 & 15 & 10 & 10 \\
\hline 6 & 58 & 42 & 40 & 39 & 22 & 21 & 13 \\
\hline 9 & 54 & 42 & 40 & 23 & 29 & 23 & 11 \\
\hline 12 & 58 & 45 & 43 & 24 & 30 & 24 & 10 \\
\hline 15 & 54 & 54 & 52 & 25 & 65 & 25 & 26 \\
\hline 18 & 55 & 55 & 33 & 32 & 44 & 43 & 31 \\
\hline 21 & 51 & 57 & 15 & 14 & 65 & 23 & 31 \\
\hline
\end{tabular}




\begin{tabular}{|c|c|c|c|c|c|c|c|}
\hline 24 & 51 & 53 & 33 & 32 & 22 & 24 & 15 \\
\hline 27 & 55 & 55 & 33 & 32 & 24 & 25 & 31 \\
\hline 30 & 52 & 48 & 46 & 45 & 19 & 16 & 35 \\
\hline 33 & 58 & 55 & 43 & 42 & 18 & 15 & 25 \\
\hline 36 & 59 & 55 & 43 & 42 & 20 & 17 & 26 \\
\hline 39 & 57 & 53 & 31 & 30 & 55 & 52 & 12 \\
\hline 42 & 58 & 55 & 23 & 22 & 30 & 27 & 25 \\
\hline 45 & 51 & 47 & 15 & 14 & 34 & 42 & 15 \\
\hline 48 & 49 & 45 & 43 & 42 & 32 & 40 & 26 \\
\hline 51 & 57 & 53 & 51 & 50 & 30 & 32 & 48 \\
\hline 54 & 69 & 65 & 63 & 62 & 46 & 45 & 44 \\
\hline 57 & 35 & 31 & 29 & 28 & 19 & 35 & 31 \\
\hline 60 & 52 & 58 & 36 & 35 & 20 & 26 & 22 \\
\hline 63 & 59 & 55 & 23 & 22 & 22 & 32 & 28 \\
\hline 66 & 57 & 53 & 51 & 50 & 24 & 25 & 15 \\
\hline 69 & 52 & 49 & 27 & 42 & 35 & 15 & 21 \\
\hline 72 & 61 & 61 & 19 & 18 & 36 & 35 & 31 \\
\hline
\end{tabular}

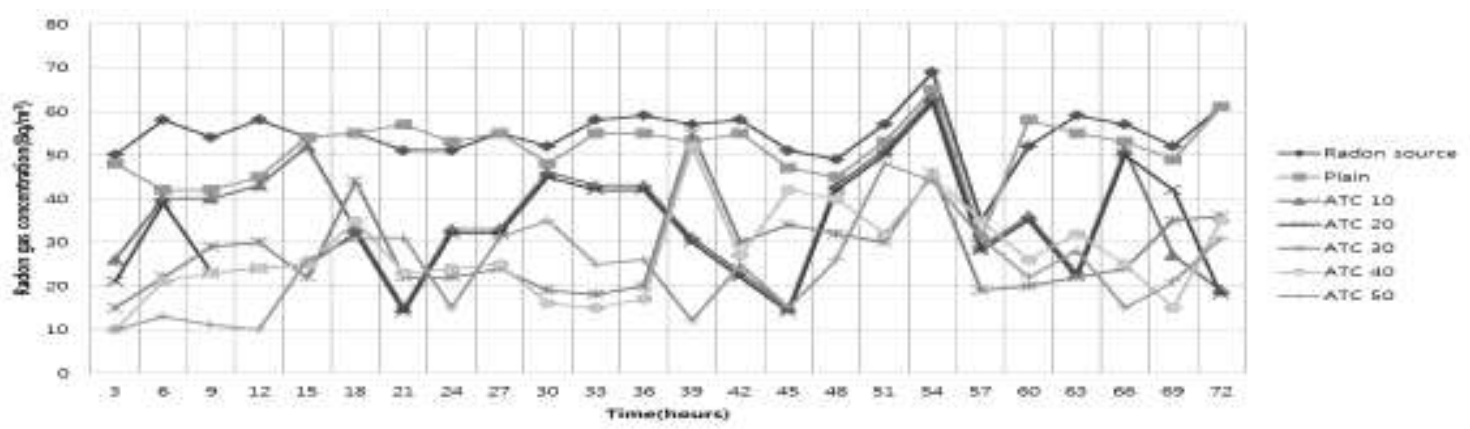

Figure 4: Graph representing mean value of radon gas concentration in chamber per hours (3days)

\subsubsection{Radon Gas Concentration to 7days (168hours)}

Next, as a result of measuring the concentration of radon gas concentration in the matrix replaced with anthracite for 7 days, the radon gas concentration in the chamber tends to decrease as the substitution ratio of anthracite increases shown in [Table 5] and [Figure 5]. There is a radon gas source in the chamber, and the radon gas concentration is increased due to the subsequent emission of radioactive atoms. However, since the average value of radon gas concentration for 12 hours is reduced according to the replacement ratio of anthracite, a certain amount of radon appears to be reduced to the surface or inside of the matrix.

Table 5: The average value of the radon gas concentration in the chamber per hours (7days)

\begin{tabular}{|c|c|c|c|c|c|c|c|}
\hline Level Time & Radon source & Plain & ATC 10 & ATC 20 & ATC 30 & ATC 40 & ATC 50 \\
\hline 12 & 58 & 45 & 43 & 24 & 30 & 24 & 10 \\
\hline 24 & 51 & 53 & 33 & 32 & 22 & 24 & 15 \\
\hline 36 & 59 & 55 & 43 & 42 & 20 & 17 & 26 \\
\hline 60 & 52 & 58 & 36 & 35 & 20 & 26 & 22 \\
\hline 72 & 61 & 61 & 19 & 18 & 36 & 35 & 31 \\
\hline 84 & 55 & 58 & 26 & 25 & 49 & 25 & 26 \\
\hline 96 & 49 & 45 & 43 & 42 & 66 & 39 & 35 \\
\hline 108 & 53 & 55 & 33 & 32 & 20 & 33 & 28 \\
\hline 120 & 57 & 48 & 46 & 45 & 24 & 38 & 32 \\
\hline 132 & 53 & 55 & 23 & 22 & 26 & 36 & 26 \\
\hline 144 & 62 & 55 & 33 & 32 & 21 & 30 & 21 \\
\hline 156 & 42 & 45 & 23 & 22 & 15 & 14 & 22 \\
\hline 168 & 58 & 44 & 53 & 52 & 22 & 16 & 20 \\
\hline
\end{tabular}

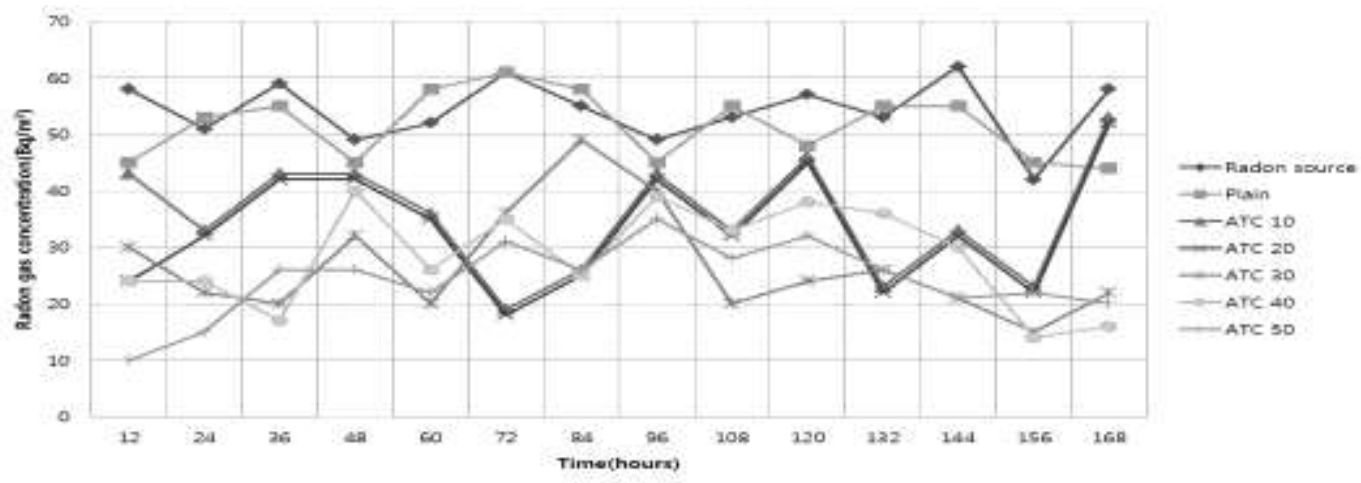

Figure 5: Graph representing mean value of radon gas concentration in chamber per hours (7days) 


\section{Conclusion}

As a result of this study, we confirmed the rate of change of the radon gas concentration in the matrix using anthracite, and the following conclusions were obtained. As the replacement ratio of anthracite increases, the radon gas concentration in the chamber is reduced and the radon gas concentration reduced to a certain level is maintained. There was no significant difference in the radon gas concentration between the 3days measurement period and the 7 days measurement period, and the radon gas concentration in the similar chamber was shown. The radon gas atom has a half-life of 3.8 days and loses its properties after this period.The reason why the measurement of the radon gas concentration was divided into 3 days and 7 days was set as the test environment considering the half-life period of radon gas.Further research is needed on the long-term measurement of radon gas concentration.

\section{Acknowledgment}

This paper was supported by the grant fund of the Korea Science and Engineering Foundation [assignment number 2015R1A2A2A01006276].

\section{References}

[1] Lee, J. H., (2011). Measures for National Health Protection from Radiation Contamination and Tasks to be Solved. The Korean Society of Environmental Health and Toxicology, 11(4), 57-82.

[2] Environmental Health Action Program, (2016).Development of Gamma-ray Technology for Indoor Radon Emission Assessment and indoor Shelter Evaluation System (2013001350006). Retrieved fromhttp://webbook.me.go.kr/DLi-File/107/5620052.pdf

[3] Radon doctor.
fromhttp://radondr.co.kr/\%EB\%9D $\% \mathrm{BC} \% \mathrm{~EB} \% 8 \mathrm{~F} \% 88$ -

fromhttp://radondr.co.kr/\%EB $\%$ EC\% $8 \mathrm{~B} \% \mathrm{~A} 4 \% \mathrm{~EB} \% 82 \% \mathrm{~B} 4-$

$\% \mathrm{EC} \% 9 \mathrm{C} \% \mathrm{~A} 0 \% \mathrm{EC} \% 9 \mathrm{E} \% 85 \% \mathrm{EC} \% 9 \mathrm{D} \% 98$

$\%$ ЕВ\%А9\%94\%ЕC\%B9\%B4\%ЕB\%8B\%88\%ЕC\%A6\%98/.html.

[4] Lim. J. S., (2012). Adsorption science engineering adsorbent. Naeha publisher Korea.

[5] Microstructure Laboratory. Department of Polymer Engineering, Pusan National University. Retrieved fromhttp://mslab.polymer.pusan.ac.kr/polymer/sub7/sub7_4.html

[6] Lee. Y. S.,(2013). Strength Characteristic according to the Curing Temperature of the Inorganic Binder Using the Industrial ByProduct. $\quad$ Korea Concrete Institute, 12(1), 235-236.

[7] Yang. H., (2015). Mechanical Properties of Lightweight Mortar in Accordance with the Particle Size and Replacement Ratio of the Wasted Tire Chip. Korean Recycled Construction Resource Institute, 03(4), 342-347.

[8] Pyeon. S. J., (2018). Evaluation of Decreasing Concentration of Radon Gas for Indoor Air Quality with Magnesium Oxide Board using Anthracite. Journal of the Korea Institute of Construction, (18)1. 9-15.

[9] Lim. H. Y., (2017). Thermal Conductivity Properties of Magnesium Oxide Matrix according to Types of Radon adsorption Materials. Korea Concrete Institute, 29(1). 611-612.

[10] Ministry of Environment. (2000). Radon measurement method Short term measurement Indoor radon measurement guide. Ministry of Environment Ordinance No. 202. Retrieved fromhttp://www.me.go.kr/home/file/readDownloadFile.do?fileId=1 642\&fileSeq=2.html. 